KHAZANAH MULTIDISIPLIN

VOL 2 NO 22021

https://journal.uinsgd.ac.id/index.php/kl

\title{
STUDI HISTORIS MENGENAI KEBIJAKAN LUAR NEGERI YANG DITERAPKAN OLEH SULTAN ABDUL HAMID II DI DINASTI OSMANI (1876-1909 M)
}

\author{
Siti Alia', Rayma Nur Falah², Salsabiila Raudhatul Jannah3, \\ Slamet Muhammad Rahmat4 \\ ${ }^{1-4}$ UIN Sunan Gunung Djati Bandung \\ Email : aliaalya267@uinsgd.ac.id
}

Diterima : 4 Maret 2021, Revisi : 15 April 2021 Disetujui : 10 May 2021

\begin{abstract}
ABSTRAK
Sultan Abdul Hamid II adalah seorang pedagang furniture dari kayu yang kemudian diangkat menjadi sultan Turki Utsmani karena kakak tirinya yang bernama Murad V yang sakit. Meskipun dirinya memerintah dengan sistem Monarki yang absolut, Abdul Hamid membuktikan jika dirinya sanggup bertahan selama 33 tahun dan memperbaiki kondisi negara yang sudah ada di ujung tanduk dengan banyak sekali kebijakan-kebijakan yang dibuatnya. Kami mengumpul data dengan metode historis, dengan mengambil interpretasi dari sumber dan keterangan secara kritis terhadap perkembangan di masanya dengan pertimbangan secara teliti. Sehingga ditemukannya Kebijakan Luar Negeri Sulta Abdul Hamid II.

Kata kunci : Kebijakan, Abdul Hamid, Dinasti Osmani
\end{abstract}

\begin{abstract}
Sultan Abdul Hamid II was a wood furniture trader who was later appointed the sultan of the Ottoman Turks because his half-brother Murad V was sick. Even though he ruled with an absolute monarchy system, Abdul Hamid proved that he was able to survive for 33 years and improve the condition of the country that was already on the brink with the various policies he made. We collect data using the historical method, taking the interpretation of sources and information critically on developments in its time with careful consideration. So the discovery of the Foreign Policy of Sultan Abdul Hamid II.
\end{abstract}

Keywords: Policy, Abdul Hamid, Osmani dynasty Dinasti

\section{PENDAHULUAN}

Abdul Hamid II diangkat menjadi sultan pada tanggal 31 Agustus tahun 1876, saat dirinya masih berusia 34 tahun (Suryadi, 2010). (Maryam dkk, Sejarah Peradaban Islam) Dia sendiri adalah Sultan ke 34, dan Sultan terakhir yang berkuasa secara absolut (Voigtländer and Voth, 2014; Datta and Mete, 2021; Qadri, 2021). Pengangkatannya sendiri mendapat banyak ucapan selamat dari berbagai kelompok. Berbeda dengan kakek dan ayahnya yang merupakan penggagas westernisasi dalam pemerintahan 
Osmani, meskipun mengagumi kemajuan teknologi di Jerman, prinsipnya dalam mengadopsi budaya Barat untuk negaranya sangatlah khusus. Abdul Hamid II tidak ingin meniru budaya dan tradisi Barat, karena berkeyakinan bahwa dunia Timur memiliki peradabannya sendiri, yaitu peradaban Islam yang lebih unggul jika dibandingkan dengan peradaban Barat (Deeb and Harb, 2013). Disamping hal itu juga, ini demi menyelamatkan negara yang sudah berada di ujung tanduk setelah terbunuhnya Abdul Aziz Han di Istana Feriye.

Meskipun baru menjabat selama setahun, beliau sudah harus berperang melawan Russia yang mengklaim dirinya sebagai penerus Byzantium, lalu mencoba memasuki wilayah Utsmani. Namun, berkat kecerdikannya, dia berhasil menghentikan usaha Rusia (Freely, 2019). Meski pada akhirnya, beliau tetap dikecam oleh anggota parlemen karena dianggap terlambat untuk meminta pendapat anggota parlemen dan membuat situasi kian buruk. Pasca perang inilah, dikarenakan kisruhnya para anggota parlemen, Abdul Hamid membekukan parlemen selama lebih dari 30 tahun lamanya. Sejarawan menamakan periode ini dengan Orde Hamidi, atau Al-'Ashr Al-Hamidi, (Assayid Muhammad Ad-Daqn) dimana kendali pemerintahan dipegang oleh Abdul Hamid tanpa adanya intervensi anggota parlemen. Humayuni merupakan peraturan yang diterapkan sebagai langkah awal Sultan Abdul Hamid dalam melaksanakan pemerintahannya, dimana beliau mencatat kebobrokan yang telah terjadi di negaranya (Noor, 2014).

Ada banyak kebijakan dalam negeri seperti kebijakan untuk mengangkat para pejabat negara, menarik pajak, mengatur dana masyarakat dan banyak lagi. Namun dalam tulisan ini, kami sebagai penulis akan lebih berfokus pada kebijakan luar negeri yang diterapkan oleh Abdul Hamid, seperti pembangunan rel kereta api, serta pernyataan beliau tentang Palestina. Hal ini dikarenakan beliau yang dilabeli sebagai Kızıl Sultan alias Sultan Merah, karena dituduh melakukan genosida pada bangsa Armenia oleh Barat, meski hal itu hanyalah fitnah belaka. Kami 
sendiri memilih topik ini sebagai pengingat, bahwa dunia pernah memiliki pemimpin muslim sehebat beliau (Hamid II, no date).

Yang membuat kami tertarik untuk membahas lebih lanjut mengenai kebijakan-kebijakan apa saja yang telah dikeluarkan oleh beliau dimasa kepemiminannya selama 33 tahun. Karena, melihat dari banyaknya upaya yang sudah dilakukan oleh Sultan Abdul Hamid II untuk mempertahankan Dinasti Osmani dan cara pengambilan keputusan yang ia ambil sangatlah berbeda jauh dengan para pendahulunya.

\section{METODE PENELITIAN}

Sesuai dengan judulnya, yang mengandung kata Studi Historis, penulis menggunakan metode historis, Menurut Muhammad Nazir metode penelitian historis adalah interpretasi dari sumber-sumber keterangan secara kritis terhadap perkembangan di masa lampau dengan pertimbangan secara teliti. Selain itu kami menggunakan metode studi pustaka sebagai metode penelitian dalam jurnal ini, pengumpulan data pustaka dengan mencatat dan mengolah bahan penelitian dalam serangkaian kegiatan (Zed, 2004). Menggunakan HotS Kami sebagai penulispun berusaha untuk mencari sumber-sumber yang kredibel dalam menyusun artikel ini, baik itu dari buku, buku elektronik, ataupun jurnal (Darmalaksana and Qomaruzzaman, 2020).

\section{HASIL DAN PEMBAHASAN}

Selama 33 tahun kepemimpinannya, Abdul Hamid telah menuai cukup banyak keberhasilan, baik itu dalam politik nasional ataupun internasional. Tapi dari sekian banyak konflik yang beliau alami, kami sebagai penulis hanya akan menyampaikan tiga peristiwa yang kami anggap memiliki andil besar dalam sejarah kepemimpinan beliau.

\section{Perang Rusia-Osmani, atau Russo-Turkish War (1877-1878)}

Meskipun sebab awal perang ini terjadi pada era ayah dan pamannya, namun Abdul Hamid harus menanggung getah dari peristiwaperistiwa yang terjadi sebelum dirinya menjabat sebagai sultan. Namun 
karena perang ini juga, Ordo Hamidi bisa dimulai dengan terjadinya pembekuan parlemen yang saat itu seolah-olah mengambil alih kendali pemerintahan.

Perang Russo-Turkish ini mempertemukan antara Dinasti Osmani dengan koalisi yang dipimpin Rusia, yang terdiri dari Serbia, Romania, Montenegro, dan Bulgaria (Braginsky, 2015). Perang yang dimenangkan oleh koalisi Rusia ini membuat Bulgaria kembali diakui sebagai negara setelah hampir lima abad ada di bawah pengaruh Osmani.

Hari penanda tanganan Perjanjian San Stefano pada tanggal 3 Maret 1878 kini dirayakan sebagai Hari Pembebasan di Bulgaria (Ĭolova et al., 1989). Meski pada akhirnya, Rusia menyatakan jika perjanjian ini hanya sementara dan bisa diubah sesuai keinginan. Perjanjian inipun direvisi oleh Perjanjian Berlin yang ditandatangani pada tanggal 13 Juli 1878 (Enh, 2010).

Karena perang ini serta Perjanjian Berlin juga yang menegaskan kemerdekaan Bulgaria, Serbia, Romania, serta Montenegro, keempat negara tersebut berhasil melepaskan diri dari Dinasti Osmani. Sementara Rusia mendapat wilayah Kars dan Batum dari Osmani.

\section{Proyek Rel Kereta Api Hijaz}

Ini adalah rel kereta api sepanjang $1322 \mathrm{~km}$ yang dibangun dari Damaskus sampai Madinah pada tahun 1900-1908 oleh Abdul Hamid (İslam ansiklopedisi). Proyek rel ini sebenarnya adalah sambungan dari Stasiun Haydarpaşa yang ada di Kadıköy, sebuah distrik di İstanbul, menuju Stasiun Damaskus dan seharusnya sampai ke Mekkah. Namun karena Perang Dunia I, penolakan Amir Mekkah, masalah dana, dan Osmani yang tidak lagi dipimpin dengan keabsolutan Sultan, rel kereta api ini terhenti di Madinah dan ditutup pada tahun 1920.

Proyek ini sudah direncanakan sekitar tahun 1860-an, namun baru terealisasi tahun 1900. Proyek ini kembali naik ke permukaan setelah ekspedisi yang dilakukan Ahmet Raşid Paşa ke Yaman pada tahun 1871- 


\section{KHAZANAH MULTIDISIPLIN}

VOL 2 NO 22021

https://journal.uinsgd.ac.id/index.php/kl

1873. Dia menyimpulkan jika transportasi yang layak untuk tentara Osmani pergi ke sana adalah kereta api. Hal yang serupa juga diutarakan Osman Nuri Paşa, yang mengatakan jika keamanan di Jazirah Arab perlu dipertahankan (İslam ansiklopedisi).

Banyak yang meragukan jika Osmani akan berhasil dalam pembangunan rel kereta api ini. Ziraat Bankası, bank negara yang mengakomodasi kepentingan agrikultur Osmani, meminjamkan 100.000 lira pada negara. Abdul Hamid sendiri tidak kehabisan akalnya dan menyeru umat untuk membantu negara dalam hal ini.

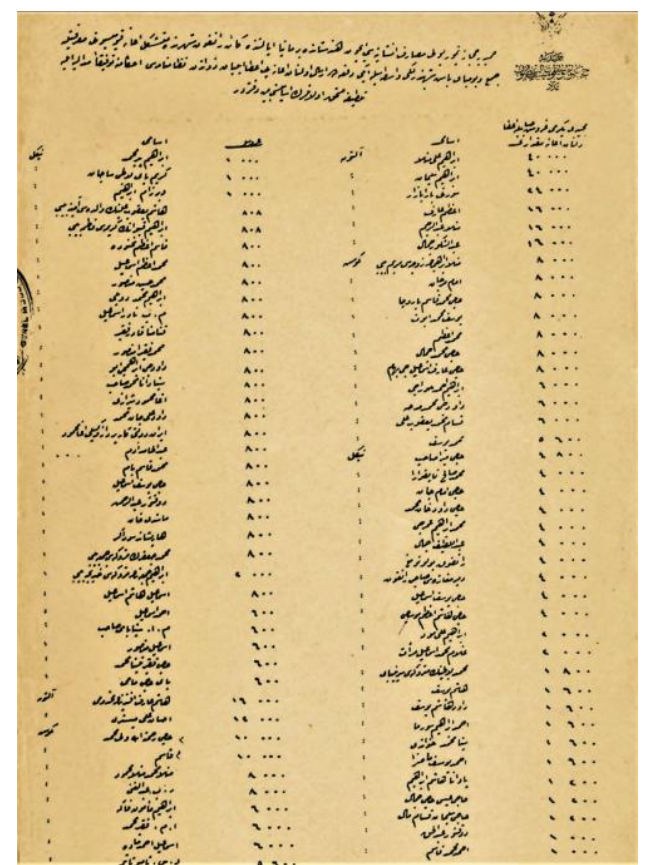

Gambar 1. Dokumen yang menunjukkan daftar donatur dari muslim India

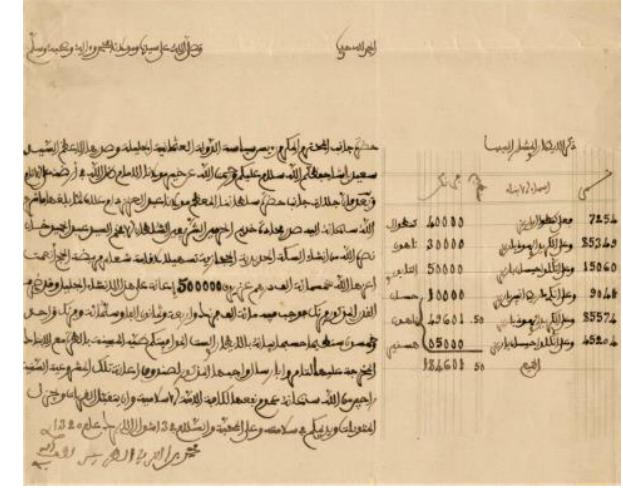

Gambar 2. Dokumen yang menunjukkan daftar donatur dari muslim Maroko 


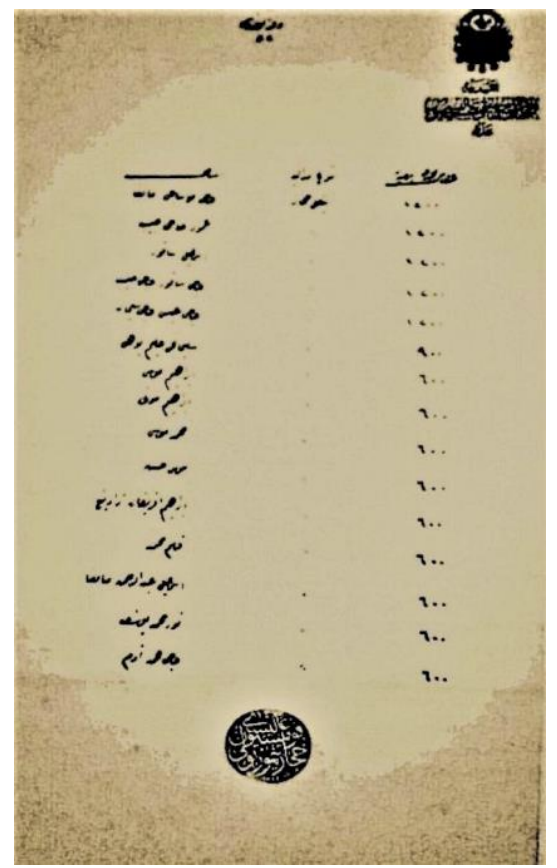

\section{Gambar 3. Dokumen yang menunjukkan daftar donatur dari muslim} Mozambik

Gambar 1,2,3 Menunjukkan kerjasama muslim dalam proyek ini, Sebetulnya proyek ini bukan hanya untuk memfasilitasi transportasi militer dan ekonomi belaka. Namun juga dalam Ibadah Haji. Karena hampir 20\% dari rombongan tidak akan sampai ke Mekkah tempo hari dikarenakan panjangnya perjalanan untuk beribadah Haji (Özyüksel, 2016).

Pada era modern, Stasiun Madinah yang menjadi stasiun terakhir dari proyek Rel Kereta Api Hijaz, kini dialih fungsikan sebagai museum. Letaknya sendiri tidak terlalu jauh dari kompleks Masjid Nabawi. Terakhir kali penulis berkunjung ke sana, interior dan eksterior Stasiun Madinah masih sangat kokoh dan asli (Salsabiila,2014).

\section{Awal Gesekan Dengan Zionis Yahudi}

Jika kita telaah lebih dalam, hanya Dinasti Osmani yang mau menerima keberadaan yahudi sejak awal. Pada tahun 1492, saat Kesultanan Andalusia runtuh dan Ferdinand I melakukan pengusiran terhadap orangorang yahudi dan muslim, Bayezid II mengirimkan Angkatan Laut di bawah pimpinan Laksamana Kemal Reis untuk mengevakuasi mereka. Para pengungsi yang datang dari Spanyol juga mendapat kewarganegaraan 
Osmani dari Bayezid II (Isri, 2020). Belum puas dengan evakuasi tersebut, Bayezid II secara terang-terangan menyindir Ferdinand I, "Kau berusaha untuk dipanggil Sang Bijak Ferdinand, tapi kau memiskinkan negaramu dan memperkaya negaraku!” (The Jewish Encyclopedia). Bahkan Bayezid II mengancam siapapun yang memberi perlakuan buruk pada Kaum Yahudi dengan hukuman mati.

Namun masa lalu tetaplah masa lalu. Lebih dari empat abad berlalu, dan segelintir kaum yahudi, yang terdiri dari Rabbi Yehuda Bibas, Zvi Hirsch Kalischer dan Judah Alkalai, mencetuskan gerakan proto-zionisme yang menjadi cikal bakal gerakan zionisme (Penkower, 1988). Berbeda dari tiga orang tersebut, muncul seorang yahudi berdarah Austria-Hungaria bernama Theodor Herzl yang dengan berani mencetuskan gerakan zionisme. Bahkan Herzl disebutkan secara eksplisit dalam Deklarasi Kemerdekaan Israel sebagai Bapak Spiritual Negara Yahudi.

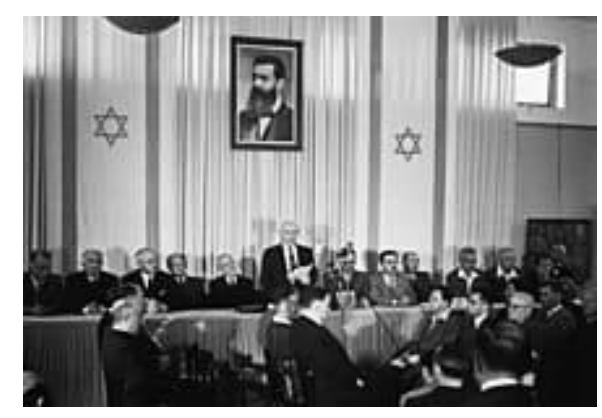

Gambar 4. David Ben-Gurion mendeklarasikan kemerdekaan di hadapan foto Theodor Herzl, pendiri zionisme modern

Gambar 4 menunjukkan mendeklarasikan kemerdekaan di hadapan foto Theodor Herzl, Sebelum berhasil bertemu dengan Abdul Hamid secara langsung, Herzl sudah berkeliling Eropa untuk memperkenalkan gerakan zionisme serta mengumpulkan suporternya. Menurut Norman Roose, Herzl sudah mengklaim dirinya sebagai Parnell untuk Yahudi (Norman Rose, 1945-1948). 10 Maret 1896, Herzl dikunjungi oleh Pendeta William Hechler, Mentri Anglikan Inggris di Kedutaan Besar Inggris di Vienna. Hechler membaca Der Judenstaat karya Herzl, dan pertemuan itu menjadi pemberian legitimasi oleh Hechler terhadap Herzl dan Zionisme (Jerry 
KHAZANAH MULTIDISIPLIN

VOL 2 NO 22021

https://journal.uinsgd.ac.id/index.php/kl

Klinger, July 2010).

Hechler juga mengatur pertemuan lanjutan dengan Frederick I, yang merupakan paman dari Kaisar Wilhelm pada bulan April tahun 1896. Berkat dukungan kedua tokoh tersebut, Herzl berhasil bertemu Wilhelm pada tahun 1898 dan mendapatkan legitimasi dari Wilhelm atas ide-idenya (London Daily Mail, Friday 18 November 1898). Pada Mei 1896, terjemahan berbahasa inggris Der Judenstaat dipublikasikan.

Pada tahun yang sama juga, Herzl pergi ke Istanbul untuk memperkenalkan idenya pada Abdul Hamid secara langsung (The Jewish State) meskipun diriya hanya bisa menjumpai orang-orang berpangkat tinggi lainnya, termasuk Wazir Agung. Hal ini sendiri karena Herzl memperkenalkan diri sebagai jurnalis dari Neue Freie Presse.

Sebelum Herzl pergi dari Istanbul pada tanggal 29 Juni 1896, secara simbolis dia dianugerahi mendali penghargaan, yaitu lencana Mecidiye (www.herzl.org) . Baru pada tanggal 17 Mei 1901, dia berhasil bertemu Abdul Hamid secara langsung. Herzl sendiri menawarkan untuk melunasi semua hutang luar negeri Osmani dengan bayaran pemberian akses bebas untuk orang-orang yahudi ke Palestina. Bayaran inipun langsung ditolak mentah-mentah oleh Abdul Hamid (Ruhullah and Qodir, 2021). Peristiwa inipun menjadi tonggak awal kenapa para pengikut Paham Zionisme teramat bersungguh-sungguh dalam menggulingkan Abdul Hamid.

\section{Peran Abdul Hamid II Dalam Perang Çanakkale}

Gambar 5 menunjukkan Potret pangkalan pada perang canakkle , Meskipun Perang Çanakkale ini berlangsung pada tahun 1915 hingga tahun 1916, namun Abdul Hamid sendiri sudah memperbaharui senjata dan membangun fasilitas yang layak di Çanakkale sejak tahun 1890-an 
(Başbakanlık Osmanlı Arşivi). Hal ini sendiri adalah faktor kemenangan Osmani pada Perang Çanakkale.

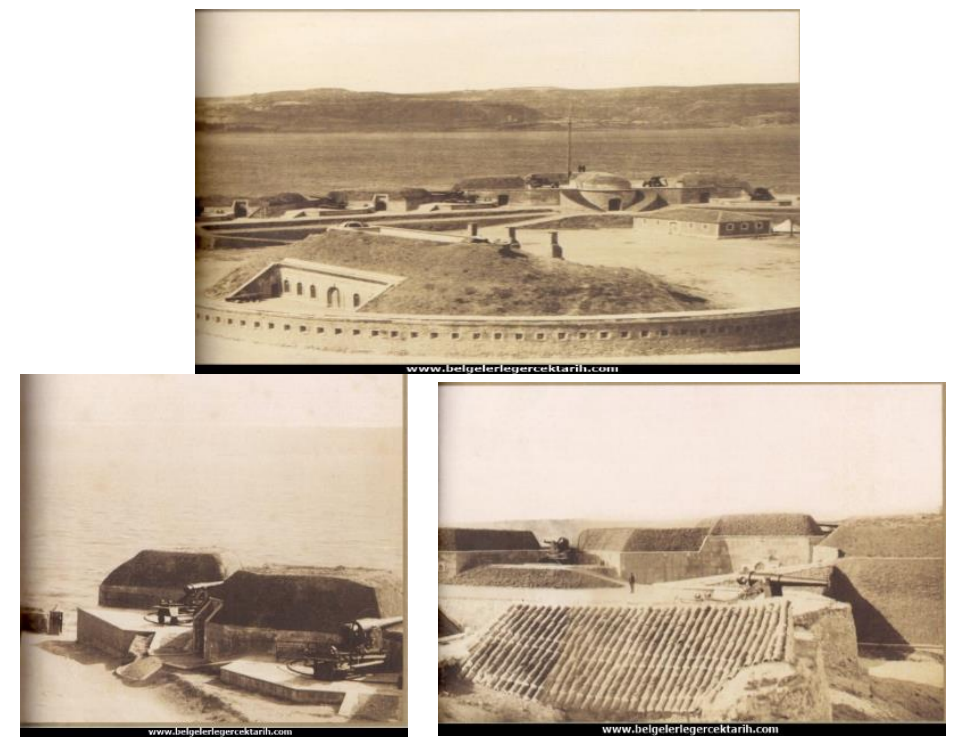

Gambar 5. Potret pangkalan pada perang canakkle

\section{SIMPULAN}

Sultan Abdul Hamid II adalah sultan Turki Utsmani yang ke-34. Selama 33 tahun kepemimpinannya beliau berhasil dalam berbagai bidang sehingga dapat memperbaiki kondisi negara yang hampir menghadapi kehancuran pada saat itu. Untuk mengembalikan kondisi ekonomi seperti semula dan untuk memperkuat pertahanan Sultan Abdul Hamid II mengeluarkan beberapa kebijakan. Seperti, membuat proyek pembangunan Rel Kereta Api Hijaz yang dibangun dari Damaskus sampai Madinah, menolak tawaran dari Herzl untuk melunasi semua hutanghutang Osmani terhadap luar negri karna dengan syarat membebaskan akses orang-orang yahudi untuk datang ke Palestina, memperbaharui senjata dan membangun fasilitas yang layak di Çanakkale untuk ikut serta dalam Perang Çanakkale yang berujung kemenangan untuk Osmani itu sendiri. Secara keseluruhan, menurut data-data yang telah kami kumpulkan, beliau sanggup memperpanjang umur kesultanan osmani dan mengembalikan sedikit wibawa negara meskipun hanya berlangsung kurang dari setengah abad. 
KHAZANAH MULTIDISIPLIN

VOL 2 NO 22021

https://journal.uinsgd.ac.id/index.php/kl

\section{DAFTAR PUSTAKA}

Braginsky, V. (2015) “Two Hundred Years after the First Embassy: Ottoman Turkey, Its Worthless Western Allies and Russian Enemies-the Worst of the Kāfirs," in The Turkic-Turkish Theme in Traditional Malay Literature. Brill, pp. 155-194.

Darmalaksana, W. and Qomaruzzaman, B. (2020) “Teologi Terapan dalam Islam: Sebuah Syarah Hadis dengan Pendekatan High Order Thinking Skill," Khazanah Theologia, 2(3), pp. 119-131.

Datta, R. and Mete, J. (2021) "AN AUTHENTIC OVERVIEW OF THE EDUCATIONAL RIGHTS AND PROSPECTS OF MUSLIM WOMEN," Khazanah Pendidikan Islam, 3(2), pp. 54-62.

Deeb, L. and Harb, M. (2013) Leisurely Islam. Princeton University Press.

Enh, A. M. (2010) "Krisis Bosnia-Herzegovina 1908: Peranan dan Reaksi Kuasa-kuasa Besar (Bosnia-Herzegovina Crisis 1908: Roles and Reactions of the Super Powers)," Akademika, 78(1).

Freely, J. (2019) Istanbul: Ibu Kota Tiga Imperium Agung Dunia (Byzantium, Romawi, dan Usmani). Pustaka Alvabet.

Hamid II, A. (no date) "Abdul Hamid II-The complete information and online sale with free shipping."

Ĭolova, G. et al. (1989) Bibliografiiāina bŭlgarskata pravna literatura: 9. IX. 1944-31. XII. 1984. Izd-vo na Bŭlgarskata akademiiāna naukite.

Isri, S. (2020) "ORIENTALISME DAN IMPLIKASI KEPADA DUNIA ISLAM,” Jurnal MUDARRISUNA: Media Kajian Pendidikan Agama Islam, 10(2), pp. 311-333.

Noor, Y. (2014) “Sejarah Timur Tengah (Asia Barat Daya)," Yogyakarta: Ombak.

Özyüksel, M. (2016) The Berlin-Baghdad Railway and the Ottoman Empire: Industrialization, Imperial Germany and the Middle East. Bloomsbury Publishing.

Penkower, M. N. (1988) The Jews Were Expendable: Free World Diplomacy and the Holocaust. Wayne State University Press.

Qadri, A. (2021) "Bencana dan Tindakan Kepedulian Sosial dalam Keberagamaan: Studi Komparasi Kitab Suci al-Qur'an dan Alkitab," Khazanah Theologia, 3(2), pp. 105-116.

Ruhullah, M. E. and Qodir, Z. (2021) "Analytical Study of Politics in Bangladesh: Ages Of Sheikh Hasina and Khaleda Zia's Dictates," International Journal of Islamic Khazanah, 11(1), pp. 1-11.

Suryadi, S. (2010) "Sepuluh surat Sultan Bima Abdul Hamid Muhammad 


\section{KHAZANAH MULTIDISIPLIN}

VOL 2 NO 22021

https://journal.uinsgd.ac.id/index.php/kl

Syah," Iman dan diplomasi: serpihan sejarah kerajaan Bima. Kepustakaan Populer Gramedia, École Française d'Extrême-Orient and ..., pp. 105-188.

Voigtländer, N. and Voth, H.-J. (2014) Highway to hitler. National Bureau of Economic Research.

Zed, M. (2004) Metode penelitian kepustakaan. Jakarta: Yayasan Obor Indonesia. 